\title{
A SINGLE-PARENT FAMILY IN THE PAST AND PRESENT
}

\author{
Irina V. Terelyanskaya \\ Volgograd State University, Volgograd, Russian Federation
}

\begin{abstract}
The article presents a theoretical and statistical analysis of the emergence of families with a single parent. Through the prism of time the author considers the contribution of such of the phenomena of social life as the parents divorce, widowhood, the birth of illegitimate children, adoption of a child by a single parent, as well as the prolonged absence of a spouse or a voluntary suspension from parenting to the statistics of the appearance of single-parent families.

The paper points out that divorce in pre-revolutionary Russia was not the most important factor in the emergence of families with a single mother or father, as it is observed in our country now. At the same time the fact of the birth of a child by a woman who is unmarried from Peter's reforms to the present day significantly increases the share of families with a single parent. The article discusses the causes of this phenomenon in the Russian Empire and in modern Russia.

The author shows how the attitude towards single fathers and single mothers has changed through the prism of laws, norms and rules of social morality in the present time and in the past. The study found out that Russian society has had different attitudes to their parents, male and female raising a child alone. During the studied period society has considered fathers as heads of single-parent families more loyally than mothers in similar circumstances. The latter, although their number prevails in the total number of families with a single parent often felt negative attitude from others, as well as from social institutions of the state and the church. In today's Russia this situation, as the author shows, occurs only at the domestic level. Legislation of the Russian Federation and social services provide material and psychological assistance to single-parent families in resolving various difficult life situations.

Key words: single-parent family, single mother, widow, widower.
\end{abstract}

УДК 364.286

ББК 60.93

\section{МОНОРОДИТЕЛЬСКАЯ СЕМЬЯ В ПРОШЛОМ И НАСТОЯЩЕМ}

\author{
Ирина Васильевна Терелянская \\ Волгоградский государственный университет, г. Волгоград, Российская Федерация
}

\begin{abstract}
Аннотация. В статье представлен теоретический и статистический анализ возникновения семей с одиноким родителем. Автор через призму времени рассматривает вклад в статистику появления монородительских семей таких явлений социальной жизни, как развод родителей, вдовство, рождение внебрачных детей, усыновление или удочерение ребенка одиноким родителем, а также длительное отсутствие одного из супругов или добровольное отстранение от воспитания детей.

В работе указывается на то, что развод в дореволюционной России не являлся важнейшим фактором в возникновении семей с одинокой матерью или отцом, как это наблюдается в нашей стране сейчас. В то же ฉे время факт рождения ребенка женщиной, не состоящей в браке, начиная с петровских реформ и до сегодняшнего дня, значительно увеличивает долю семей с одиноким родителем. В статье рассматриваются причины такого явления в Российской империи и в современной России.

Автор показывает, как менялось отношение к одиноким отцам и одиноким матерям через призму законов, норм и правил общественной морали в настоящем времени и в прошлом. Исследование выявило, что российское общество по-разному относилось к родителям мужского и женского пола, воспитывающим ठ․ ребенка в одиночку. На отцов - глав монородительских семей общество на протяжении исследуемого пери(.) ода смотрело более лояльно, чем на матерей, оказавшихся в подобных условиях. Последние, хотя их количе-
\end{abstract}




\section{РОССИЙСКАЯ СЕМЬЯ}

ство преобладает в общей численности семей с одиноким родителем, чаще чувствовали отрицательное отношение со стороны окружающих, а также социальных институтов в лице государства и церкви. В сегодняшней России такое положение дел, как показывает автор, встречается только на бытовом уровне. Законодательство Российской Федерации и социальные службы оказывают материальную и психологическую помощь неполным семьям в разрешении различных трудных жизненных ситуаций.

Ключевые слова: монородительская семья, семья с одиноким родителем, мать-одиночка, вдова, вдовец.

Тысячелетия в человеческом обществе существует семья. Тайна ее долголетия заключается в том, что семья - это связующая нить между личностью и обществом. Только семья, как часть культуры, способствует эффективной социализации каждого ее члена в окружающем мире.

Семья играет огромную роль в судьбе не только отдельного человека, но общества в целом. Успешное выполнение семьей ее функций влияет на становление и развитие каждой конкретной личности, на качество и количество трудовых ресурсов в обществе, а в конечном итоге на условия жизни во всем государстве.

В России, как и во всем мире, основные демографические тенденции таковы, что удельный вес семей с одним родителем, то есть монородительских семей, год от года увеличивается. В таких семьях все бремя ответственности за воспитание детей, выполнение экономическо-бытовых, социальных, эмоционально-психологических, духовно-ценностных и других функций ложится только на одного родителя [13].

Всероссийская перепись населения Российской Федерации 2010 г. показала, что в нашей стране на тот момент насчитывалось 17555160 семей. Из них 5742017 семей составляли одинокие родители, воспитывающие детей до 18 лет. То есть одна треть всех российских семей - монородительские. 5087048 семей возглавляли женщины-матери (88,6 \% от всех монородительских семей) и 648000 - одинокие отцы (11,4\%) [10, с. 29].

Существуют семьи, где родителей деюре двое, но де-факто воспитывает ребенка только один из супругов, так как второй продолжительное время отсутствует вовсе или не занимается ребенком. К таким случаям мы можем отнести родителя, пропавшего без вести, находящегося в местах заключения, ведущего аморальный образ жизни, лишенного родительских прав.
«Условно монородительскими» можно назвать семьи, где один из родителей надолго покидает семью - работа вахтовым методом, длительные командировки, удаленное место работы и т. п. Подсчет этих семей Росстатом не ведется. И даже сложно предположить, какой процент детей воспитывается в таких семьях. Но, тем не менее, члены этих семей сталкиваются с теми же самыми проблемами, что и монородительские семьи.

Все эти проблемы можно условно разделить на две категории: экономические и психологические.

К экономическим можно отнести бытовые и материальные проблемы, а к психологическим - особенности воспитания детей при отсутствии второго родителя, моральную и эмоциональную поддержку всех членов семьи, принятие духовных и культурных ценностей, как семейных, так и общечеловеческих.

Хотя большинство разведенных женщин, воспитывающих в одиночку ребенка, имеют право на алименты со стороны мужей, но эта материальная помощь нередко не покрывает всех расходов на содержание ребенка, поступает не всегда регулярно, а порой не достается вовсе. Так, на 1 января 2017 г. в судах находилось 874800 дел о взыскании алиментов [9]. Это составляет $81,9 \%$ от всех разведенных женщин с детьми. Государство вынуждено применять к должникам не только меры административного и уголовного воздействия, такие как штрафы, административные работы, арест, но и лишение водительских прав, а также запрет выезда за границу.

Мать-одиночка не может рассчитывать даже на алименты. Со стороны государства она получает мизерное пособие по содержанию детей и порой находится на грани бедности.

Социологи, педагоги и психологи отмечают, что у большинства монородительских семей наблюдается тяжелое материальное положение, плохие жилищные условия, неудовлетворительное социально-экономическое са- 
мочувствие. Родителям в таких семьях труднее устроиться на работу, тем более высокооплачиваемую, что влечет за собой некачественное питание и медицинское обслуживание членов семей, проблемы с получением хорошего образования и воспитания для детей и т. п. [14].

Исследование российского экономиста C.В. Захарова показало, что одинокие матери проявляют более высокую экономическую активность в 1,11 чаще, чем замужние женщины. Но, тем не менее, субъективная оценка собственного уровня жизни у женщин в монородительской семье ниже. С.В. Захаров в статье «Одинокое материнство в России» отмечает, что несмотря на повышенную трудовую активность одиноких матерей, заметно большую представленность родственников в их домохозяйствах и наличие у многих из них межсемейных поддерживающих трансфертов, одиноким матерям не удается полностью компенсировать недостаток второго дохода, который мог бы поступать от отца/супруга, проживающего в домохозяйстве [5].

Но материальные проблемы не единственные, с которыми сталкивается одинокий родитель, особенно женщина. В нашем обществе придается большое значение браку, и люди, по каким-либо причинам оказавшиеся вне брачных уз, чувствуют себя изгоями, униженными со стороны общества. Это в основном относится к одиноким матерям. К отцам, в одиночку воспитывающим детей, в нашей стране отношение благосклонное. С одной стороны, это происходит из-за того, что количество одиноких отцов не сопоставимо с армией одиноких матерей, и находится в соотношении 1 к 9. А с другой, период одиночества у мужчинотцов краток, так как в России наблюдается острый дефицит мужчин. Число холостых мужчин старше 16 лет на 109000 человек меньше, чем незамужних женщин этого же возраста.

А вот отношение к одиноким матерям в России не такое лояльное и понимающее, как к отцам. Российский психолог А.И. Еремеева обнаружила, что к матерям, в одиночку воспитывающим детей, замужние женщины относятся предвзято. Они убеждены, что одиночки используют свое особое положение на рабочем месте, чтобы решить проблемы в личной жизни, а детей воспитывают дедуш- ки и бабушки. Незамужние же женщины сочувствуют одиноким матерям, считают, что последним тяжело материально и очень трудно найти мужа, имея «хвостом» ребенка. Сами одинокие матери достаточно высоко оценивают себя. Считают, что они «мировые женщины» с «сильным характером». Замужние дамы предлагают негативно окрашенные ассоциации с одинокими матерями: «матьодна ночка», «брошенная». Незамужние женщины более терпимо относятся к одиноким мамам, делая акцент в первую очередь на ребенке: «мать-отец», «жизнь только для ребенка» [3, с. 58].

Но, несмотря на проблемы, с которыми сталкиваются монородительские семьи в современной России, они согласно Конституции РФ обладают такими же социальными и правовыми гарантиями, как и семьи с двумя родителями. Дети из семей обоих типов так же не ущемляются в нашем государстве в правах и ничем не отличаются друг от друга. Но еще в начале XX в. российское общество занимало предвзятую позицию к одинокому родительству, особенно материнству.

Чтобы оценить разницу в отношениях к монородительским семьям в прошлом и настоящем, рассмотрим факторы, которые приводят к появлению таких семей:

1) развод супругов, в результате которого один из них остается с детьми;

2) женщина рожает ребенка не будучи в браке;

3) один из родителей умирает (вдовство);

4) одинокие мужчина или женщина усыновляют (удочеряют) ребенка.

Добавим сюда пятый пункт:

5) длительное отсутствие одного из супругов.

По данным на 2014 г. самое большое число семей с одним родителем, по мнению Росстата, $-41,5 \%$, появляется из-за развода или разъезда, то есть официально незарегистрированного развода, супругов. Из них одинокие отцы составляют только 8,5 \% [4, с. 34-35].

Но в начале прошлого века развод в Российской империи был малораспространенным явлением. Против яростно выступала православная церковь. В Евангелие от Матфея читаем: «А Я говорю вам: кто разводится с женою своею, кроме вины прелюбодеяния, тот 
подает ей повод прелюбодействовать; и кто женится на разведенной, тот прелюбодействует» [Матф. 5:32]. На этом основании вплоть до XIX в. прошение о разводе согласовывалось у епархиального архиерея, затем получалось разрешение в духовной канцелярии, с 1806 г. этими вопросами ведал священный Синод. Процедура была долгая и трудоемкая и приводила к наложению епитимьи, а также к семилетнему поражению в правах, включая возможность в это время заключить новый церковный брак.

Чтобы преодолеть это препятствие, от неугодных жен избавлялись побоями, голодом, постригом. Так, из книги «Русская старина» С.Е. Оспатовича 1877 г. узнаем, что прадед А.С. Пушкина - Абрам Петрович Ганнибал, заподозрив свою жену Евдокию Диопер в измене, истязал ее в особой комнате, где «в стены, повыше роста человеческаго, ввернуты были кольца. Туда вкладывались руки несчастной и ея тело повисало на воздухе. В комнате заранее приготовлены были розги, батоги, плети и муж “бил и мучил несчастную смертельными побоями необычно", принуждая ее, чтобы она на суде при допросах показала, будто "с кондуктором Шишковым хотела его, Ганнибала, отравить и с ним, Шишковым, блуд чинила"» [8]. В течение двух десятков лет, с 1732 по 1753 г., жена Ганнибала терпела мучения и голод, а после развода была выслана в монастырь [8].

Постриг в монахини свою первую супругу Соломонию Сабурову в 1526 г. русский князь Василий III Иванович, а его внук - Иван Грозный - в 1578 г. так же поступил со своей четвертой женой - Анной Алексеевной Колтовской. Нелюбимая супруга Петра I Евдокия Федоровна Лопухина тоже была отправлена своим мужем монашествовать в Суздальско-Покровский женский монастырь.

Несмотря на противоборство церкви, на Руси официальный развод все же существовал. К нему могли прибегнуть, если один из супругов отсутствовал более пяти лет, был осужден и лишен состояния, был неспособен к брачному сожитию, прелюбодействовал или был бесплоден.

Но этими поводами разрушить брачные узы пользовались в основном мужчины. Женщина была имущественно незащищена, так как никакой собственности, кроме своего приданого, не имела. При разводе ребенок оставался с отцом, ибо мать была финансово и юридически несостоятельной. При разводе женщина отвергалась социумом, теряла финансовую поддержку семьи, и не имела возможности воспитывать ребенка. Для многих женщин такое положение было невыносимо. Именно страдания отвергнутой высшим обществом Анны Карениной, описанные Л.Н. Толстым, заставили ее броситься под поезд. Развод для женщины означал социальную смерть, поэтому она так крепко держалась даже за опостылевший брак. Известно, что в 1913 г. на двадцать тысяч брачных союзов приходилось всего три развода [5].

Вследствие этого до XX в. развод в России был весьма редким событием, и не играл особой роли в появлении монородительских семей.

На сегодняшний день в Российской Федерации 19,36 \% одиноких семей появляется в результате рождения ребенка матерью, не состоящей в браке, а также усыновление или удочерение ребенка одиноким родителем. К сожалению, Росстат не стратифицирует эти семьи. Известно лишь, что в $96,4 \%$ из них главой семьи являются женщины [4, с. 34-35].

На Руси появление ребенка вне церковного благословления считалось страшным грехом - блудом. В Евангелии от Матфея есть следующие строки: «Вы слышали, что сказано древним: не прелюбодействуй. А Я говорю вам, что всякий, кто смотрит на женщину с вожделением, уже прелюбодействовал с нею в сердце своем» [Матф. 5:27, 5:28]. По мнению Иоанна Кассиана Римского, блуд входит в восьмерку главных человеческих пороков, таких как многоядение, сребролюбие, блуд, гнев, уныние, печаль, гордость и тщеславие.

Так как в таких случаях ребенок всегда оставался с матерью, то вся ответственность за «блуд» и «байстрюка» ложилась на плечи женщины. Духовенство не допускало матерейодиночек в церковь и порой отказывалось крестить их детей. Поэтому женщины предпочитали избавляться от таких младенцев, а не нести клеймо «распутницы». Мать-одиночка, запятнавшая себя и свою семью появлением внебрачного ребенка, уже не имела возможности выйти замуж и создать семью. Она 
либо на всю жизнь оставалась в доме родителей изгоем-приживалкой, либо изгонялась из семьи вместе с ребенком.

В то же самое время общественная мораль не сильно заботилась о нравственности мужчины, имевшем потомство на стороне. Жизнь незамужней матери была так ужасна, что, если у женщины не хватало мужества покончить жизнь самоубийством, то она старалась скрыть свою беременность до родов, а затем убивала младенца. Иногда новорожденных подкидывали в церковь или к богатым людям, потому что по статусу подкидыш был выше незаконнорожденного ребенка. Подкидыш считался круглой сиротой и находился под опекой церкви и государства, а байстрюк был морально, юридически не защищен. Он не наследовал не только имущество своего отца, но и матери. Будучи взрослым, он не мог служить на государственной службе или быть священником. Незаконнорожденную девушку никто не рассматривал в качестве достойной невесты. А по церковным канонам, если священник женился на такой, то его лишали сана.

Рожденный вне брака ребенок в официальных документах именовался «зазорным» и не имел отчества. Нередко священники в метриках писали таким детям позорные фамилии - Безбатьковщина, Выстирок, Замарыш, Иудин, Курвенок, Христарадин и т. п. Даже если мать-одиночку брали замуж, ее ребенок все равно не получал отчества и фамилии приемного отца. Незаконнорожденный мог носить фамилию матери или отчима с приставками «пол-», «полу-»: Половинкин, Полуанин, так как считался наполовину чужим в этой семье.

Несмотря на религиозное и общественное порицание, внебрачных детей на Руси было много. Виной этому было не только отсутствие противозачаточных средств, но и государственная политика того времени. Так, всплеск рождения незаконнорожденных детей пришелся на XVIII век [1]. Реформы Петра I привели к созданию регулярной армии. Рекрутчина в народе считалась смертным приговором солдату и его жене. 25 лет тяжелой военной службы не оставляли воину никакой надежды увидеть когда-нибудь свою семью. А его жену ждало бесправие и нищета. Такую женщину называли «соломенной вдовой». Но вдовой быть на Руси все же было легче, так как вдова при известной доле везения могла выйти замуж вновь, а солдатку впереди ожидало только одиночество и всеобщая неприязнь. «Постоянно оскорбляемая, пренебрегаемая и без средств к существованию, она считалась распущенной женщиной, которая пьет и производит на свет незаконнорожденных детей» [12]. В этом была доля истины. Не выдержав сексуального воздержания, соломенные вдовы рожали детей, обрекая тем самым себя и свое потомство на мучения. Даже если муж возвращался, это становилось для женщины не меньшей трагедией, так как муж, вернувшийся со службы, имел право убить или покалечить неверную жену и приплод. Ребенок, рожденный у солдатки, считался законнорожденным. Если это был мальчик, то его сразу же приписывали к полку, и его ждала участь его отца. Поэтому матери нередко скрывали свою беременность. Уходили рожать в другое село, а потом приносили ребенка, называя его подкидышем.

Вторым фактором, дающим большое количество незаконнорожденных детей, была крепостная зависимость. Многие источники ссылаются на то, что у помещиков были собственные «гаремы» из крепостных девушек.

На рубеже XVIII-XIX вв. убийств внебрачных детей среди крестьянок и солдаток было так много, что власти издали указы о запрете на детоубийство незаконнорожденных, а также о создании специальных «казенных» приютов для подкинутых детей. «В Москве и других городах действовали госпитали для зазорных детей, в которых с целью снижения количества детоубийств была введена практика “тайного приноса” младенцев через окно, чтобы сохранить анонимность» [1]. Почти 80 \% приютских детей умирало, не достигнув $12-13$ лет. Поэтому уже в 10 лет мальчиков отдавали на службу юнгами во флот, а девочек в работницы на фабрики [1].

Если к одинокой женщине и ее ребенку отношение было крайне негативное, то мужчина-отец в этом случае не упоминался вовсе, или даже поощрялся общественным мнением. Так, ходила поговорка, что у солдата на каждом постое по ребенку.

Следовательно, согласно историческим документам и современным статистическим 
данным, появление одиноких семей вследствие рождения ребенка у матери-одиночки и в прошлом и в настоящем времени - довольно распространенное явление.

Рассмотрим еще один фактор появления одинокого родительства - вдовство.

По данным Росстата в результате вдовства возникают 9,21\% семей с одиноким родителем. На долю вдов приходится 87,5 \% [4, c. 34-35].

Примерно такая же картина наблюдалась и в XIX веке. Переписи населения того времени говорят о том, что в деревнях было около $10 \%$ вдов и 4-5\% вдовцов [2].

Православная вера разрешает своим адептам заключать не более двух браков. Поэтому, если человек вдовел дважды, третий брак признавался незаконным, и общество обрекало его на одиночество.

Но и тут отношение к мужчинам-вдовцам и женщинам-вдовам было разным.

Эта разница особенно ярко проявляется в фольклоре. Например, в сказке «Иван, вдовий сын» говорится, как к вдове с малолетним сыном сватается купец, замучивший и сморивший голодом двух своих жен. Но, тем не менее, «подумала, подумала вдовица: "ХУдая про жениха слава катится, а идти надо. Чего станешь делать, коли жить нечем! Пойду. Каково самой горько ни приведется, а хоть сына подращу”» [6, с. 19].

Такое отношение вдовы к собственной судьбе проявилось неспроста. Женщина в те времена была юридически полностью зависима от отца или мужа. Если супруг умирал, то имущество семьи доставалось взрослым сыновьям или родственникам мужа. Одинокая женщина по статусу становилась равной сиротам или старым девам. То есть становилась социально ущербным членом общества, приживалкой в семье мужа. Нередко ее принуждали постричься в монахини и уйти в монастырь. Отношение к ней было сдержаннонегативным, как к «лишнему рту». Особо относилось общество к моральному облику вдовы. Она должна была хранить верность умершему мужу. Летописи XIV в. донесли до нас рассказ о том, как взрослые сыновья вдовой княгини Евдокии Дмитриевны, жены Дмитрия Донского, поверив наветам людской молвы, призвали мать к ответу. Чтобы отстоять свое доброе имя, Евдокия Донская вынуждена была обнажить перед сыновьями свою иссохшую от поста и вериг грудь. Как видим, даже княжеский сан не давал женщине свободу во вдовстве [7].

Мужчина-вдовец терял только хозяйку и жену - статус и имущество оставались при нем. Детей на воспитание брала бабушка или незамужние родственницы отца. Вероятно, именно поэтому в русском языке даже отсутствует слово, обозначающее ребенка, оставшегося без матери. Слово с негативной окраской - «безотцовщина» - обозначает ребенка, потерявшего отца. Оставшегося без матери ребенка воспитывал отец и его родительская семья. Покровительство отца давало физическую и психологическую защиту детям, поэтому воспринималось обществом не так остро. Если же у ребенка не оставалось обоих родителей, то это было подлинное горе. Его называли «сиротой». Обидеть сироту грех, так как считалось, что бог проявляет особое внимание к сиротам, вдовам и всем нуждающимся. Если ребенка, оставшегося без родителей, не брала на воспитание семья отца или матери, то его отправляли в сиротский дом.

Таким образом, видно, что на Руси отношение общества к одинокому мужскому родительству было гораздо терпимее и лояльнее, чем к женскому.

Следует отметить еще один фактор: из всех монородительских семей на сегодняшний день считают себя одинокими родителями $23,7 \%$ человек, состоящих в зарегистрированном, и $5,35 \%$, состоящих в незарегистрированном браке людей. Из них оценивают себя как одиноких $-79,8$ и $87,4 \%$ женщин соответственно [4, с. 34-35].

Конечно, на Руси тоже были случаи, когда кормилец семьи отправлялся на заработки, или пропадал без вести, или находился на длительных сроках заключения и не принимал участие в воспитании детей. Но семья в этом случае редко становилась монородительской, так как нуклеарных семей было крайне мало. Крестьянская семья по обыкновению включала в себя родителей, холостых и женатых сыновей с семьями, незамужних дочерей, внуков. В дворянских семьях к составу приписывались еще и няни, гувернантки и прочая челядь. Поэтому 
случаи, когда ребенок воспитывался одним родителем в семье, освященной браком (кроме солдатских), были крайне редки.

Россия до XX в. поддерживала одиноких родителей незначительно. На государственные пособия и поддержку, например бесплатное обучение, могли рассчитывать только вдовы солдатские или госслужащих. Остальные категории населения вынуждены были заботиться о себе сами или ожидать помощи со стороны церкви или богатых граждан.

В сегодняшней России в связи с неблагополучным положением монородительской семьи существует целенаправленная государственная социальная политика помощи таким семьям [11, с. 38-39]. Цель данной политики - уменьшить воздействие стресса на семью с одиноким родителем, помочь преодолеть жизненные трудности, которые семья не способна разрешить за счет собственных внутренних ресурсов.

\section{СПИСОК ЛИТЕРАТУРЫ}

1. Антонова, В. Как на Руси обходились с внебрачными детьми? / В. Антонова // Собеседник.ru. 2012. - Электрон. текстовые дан. - Режим доступа: https://sobesednik.ru/incident/20120513-kak-na-rusiobkhodilis-s-vnebrachnymi-detmi (дата обращения: 09.12.2017). - Загл. с экрана.

2. Антонова, В. Как относились к вдовам на Руси? / В. Антонова // Русская Семерка. - 2012. Электрон. текстовые дан. - Режим доступа: https:// sobesednik.ru/incident/20120513-kak-na-rusiobkhodilis-s-vnebrachnymi-detmi (дата обращения: 09.12.2017). - Загл. с экрана.

3. Еремеева, А. И. Социальные представления современных женщин об одиноком материнстве : дис. ... канд. психол. наук / Еремеева Анастасия Игоревна. - М., 2016. - 177 c.

4. Женщины и мужчины в России. 2016 : стат. сб. / под ред. К. Э. Лайкам. - М. : Росстат, 2016. $208 \mathrm{c}$.

5. Захаров, С. В. Одинокое материнство в России / С. В. Захаров // Демоскоп. - 2013. - № 553554. - C. $1-21$.

6. Нечаев, А. Н. Русские народные сказки / А. Н. Нечаев. - М. : Речь, 2017. - 317 c.

7. Пушкарева, Н. Проникнутая духом благочестия. К 600-летию со дня смерти благоверной княгини Евдокии Дмитриевны / Н. Пушкарева // Встреча с православием. - Электрон. текстовые дан. Режим доступа: http://www.pravoslavie.ru/put/ 070529183747.htm (дата обращения: 09.12.2017). Загл. с экрана.

8. Скелеты в семейном шкафу: Кто из предков Пушкина был русским Отелло, а кто Маркизом де Садом // Культурология.РФ. - Электрон. текстовые дан. - Режим доступа: https://kulturologia.ru/ blogs/171117/36682/ (дата обращения: 09.12.2017). Загл. с экрана.

9. Степовой, Б. Алиментщики отдадут долги взрослым детям. 13.03.2017 / Б. Степовой // Известия. Электрон. текстовые дан. - Режим доступа: https:// iz.ru/news/670123 (дата обращения: 09.12.2017). - Загл. с экрана.

10. Социально-демографический портрет России: По итогам Всероссийской переписи населения 2010 года // Федер. служба гос. статистики. М. : ИИЦ «Статистика России», 2012. - 183 с.

11. Терелянская, И. В. Формы проявления доверия: доверие к себе, к другим, к миру / И. В. Терелянская // Materiály XII mezinárodní vědeckopraktická konference «Aktuální vědecké vymoženosti2016». T. 8. Psychologie a sociologie. - Praha : Publishing House «Education and Science» s.r.o, 2016. - C. 36-42.

12. Щербинин, П. П. «Соломенная вдова»: права и жизнь российской солдатки / П. П. Щербинин // Семейный узы: модели для сборки : сб. ст. Кн. 1 / сост. и ред. С. Ушакин. - М. : Новое литературное обозрение, 2004. - С. 335-359.

13. Brian,T. Flight Plan: The Real Secret of Success / T. Brian. - Oakland : Berrett-Koehler Publishers, 2008. $-120 \mathrm{p}$.

14. Kurisheva, I. V. Fundamental psychophysiology of music therapy of neurological diseases / I. V. Kurisheva // International Journal of Psychophysiology. - 2008. Vol. 69, №3.-P. 302.

\section{REFERENCES}

1. Antonova V. Kak na Rusi obkhodilis s vnebrachnymi detmi? [What Russia Did with Children Born out of Wedlock?]. Sobesednik.ru. 2012. URL: https://sobesednik.ru/incident/20120513-kak-na-rusiobkhodilis-s-vnebrachnymi-detmi/. (accessed December 9, 2017).

2. Antonova V. Kak otnosilis k vdovam na Rusi? [How Widows Were Treated in Rus?]. Russkaya Semerka. 2012. URL: https://sobesednik.ru/incident/ 20120513-kak-na-rusi-obkhodilis-s-vnebrachnymidetmi/. (accessed December 9, 2017).

3. Eremeeva A.I. Sotsialnye predstavleniya sovremennykh zhenshchin ob odinokom materinstve: dis.... kand. psikhol. nauk [Social Representations of Modern Women about Single Motherhood. Cand. psychol. sci. diss.]. Moscow, 2016. 177 p. 


\section{РОССИЙСКАЯ СЕМЬЯ}

4. Laykam K.E., ed. Zhenshchiny i muzhchiny v Rossii. 2016 : stat. sb. [Women and Men in Russia. 2016: a Statistical Compendium]. Moscow, 2016. 208 p.

5. Zakharov S.V. Odinokoe materinstvo v Rossii [Single Motherhood in Russia]. Demoskop, 2013, no. 553-554, pp. 1-21.

6. Nechaev A.N. Russkie narodnye skazki [Russian Folk Tales]. Moscow, Rech Publ., 2017. 317 p.

7. Pushkareva N. Proniknutaya dukhom blagochestiya. K 600-letiyu so dnya smerti blagovernoy knyagini Evdokii Dmitrievny [Imbued with the Spirit of Piety. To the $600^{\text {th }}$ Death Anniversary of Nobleborn Princess Evdokia Dmitrievna]. Vstrecha s pravoslaviem [Meeting with Orthodoxy]. URL: http:// www.pravoslavie.ru/put/070529183747.htm. (accessed December 9, 2017).

8. Skelety v semeynom shkafu: Kto iz predkov Pushkina byl russkim Otello, a kto Markizom de Sadom [Skeletons in the Family Closet: Who of the Pushkin's Ancestors was a Russian Othello, and who Was the Marquis de Sade]. Kulturologiya.RF. URL: https:// kulturologia.ru/blogs/171117/36682/. (accessed December 9, 2017).

9. Stepovoy B. Alimentshchiki otdadut dolgi vzroslym detyam. 13.03.2017 [Deadbeat Fathers Will Pay Child Support to Adult Children]. Izvestiya. URL: https:// iz.ru/news/670123. (accessed December 9, 2017).
10. Sotsialno-demograficheskiy portret Rossii: Po itogam Vserossiyskoy perepisi naseleniya 2010 goda [Socio-Demographic Portrait of Russia: On the Results of the National Census 2010]. Federalnaya sluzhba gosudarstvennoy statistiki [Federal State Statistics Service]. Moscow, IITs «Statistika Rossii» Publ., 2012. $183 \mathrm{p}$.

11. Terelyanskaya I.V. Formy proyavleniya doveriya: doverie $k$ sebe, $k$ drugim, $k$ miru [Forms of Trust: Trust in Oneself, in Others, in the World]. Materiály XII mezinárodní vědecko-praktická konference "Aktuální vědecké vymoženosti-2016» [XII International Scientific-Practical Conference "Current Problems of Science"]. Praha, Psychologie a sociologie, 2016, vol. 8, pp. 36-42.

12. Shcherbinin P.P. «Solomennaya vdova»: prava i zhizn rossiyskoy soldatki ["Straw Widow": the Rights and the Life of a Russian Woman Soldier]. Ushakin S., ed. Semeynyy uzy: modeli dlya sborki : sb. st. Kn. 1. [Family ties: models for Assembly: Collection of articles]. Moscow, Novoe literaturnoe obozrenie Publ., 2004, pp. 335-359.

13. Brian T. Flight Plan: The Real Secret of Success. Oakland, Berrett-Koehler Publishers, 2008. 120 p.

14. Kurisheva I.V. Fundamental psychophysiology of music therapy of neurological diseases. International Journal of Psychophysiology, 2008, vol. 69, no. 3, p. 302.

\section{Information about the Author}

Irina V. Terelyanskaya, Candidate of Psychological Sciences, Associate Professor, Department of Psychology, Volgograd State University, Prosp. Universitetsky, 100, 400062 Volgograd, Russian Federation, irina.terelyanskaya@yandex.ru, psihology@vgafk.ru.

\section{Информация об авторе}

Ирина Васильевна Терелянская, кандидат психологических наук, доцент кафедры психологии, Волгоградский государственный университет, просп. Университетский, 100, 400062 г. Волгоград, Российская Федерация, irina.terelyanskaya@yandex.ru, psihology@vgafk.ru. 